\title{
A COMMENT
}

by Walter Stahel*

Lidgren / Skogh's paper is correct, in the sense that it gives the view of today's industrial economy which is trying to come to grips with the end-of-pipe waste problems. Traditional economics is about optimizing the manufacturing of goods in a linear structure up to the point of sale (P.O.S.), where ownership and liability are passed to a lay person, the consumer. In order to be competitive, the minimization of costs from the extraction of raw materials to the P.O.S. is essential. Traditionally, the costs for end-of-pipe disposal were financed by the tax payer, and disposal organized by the State. A partial transfer of this cost and obligation to the producer (under an extended producer's responsibility) will first lead to strategies of how to minimize recycling costs, in the logic of a linear structure from cradle to P.O.S. to grave. But, recycling may require huge funds in the future, as pointed out by Lidgren / Skogh - the finance of which is uncertain.

A different view is taken by the proponents of the new service economy, which sells the performance and utilization of goods rather than the goods itself. Structurally, the service economy is an 'economy in loops'; the ownership of goods remains with economic actors in the form of e.g. fleet managers; this includes a product responsibility (and liability) from cradle back to cradle; the P.O.S. is one of services instead of goods. In this context, the goods in the market are the main assets, and the central economic objective becomes therefore the management of these assets. The central notion of value is now the utilization value, not the exchange value (at the P.O.S.) of the industrial economy.

In the service economy, the 'end of life' problem explained by Lidgren / Skogh is no longer one of minimizing recycling costs, but becomes an 'end of loop' opportunity of maximizing profits from the re-marketing of used components and goods. The widely accepted axiom of 'value added' teaches us that any component has a higher value than the sum of its materials, and any good has a higher value than the sum of its components. An economic actor that can maintain the existing value of goods or components will therefore be more competitive in the world markets than a firm recycling the materials of these goods, independently of however efficient it may do this (keeping the laws of thermodynamics in mind).

The paper by Lidgren / Skogh does show the huge economic incentive for waste prevention, and the competitive advantage to be gained by not having to spend the huge amounts mentioned for recycling, nor having to create funds in order to guarantee recycling in cases in which the producer has disappeared. In conclusion, not recycling laws are needed, but strict take-back liability for manufacturers, such as sketched out in the new German waste law (called 'Kreislaufwirtschaftsgesetz', «law of an economy in loops»). In fact, a product take-back liability is only relevant for goods, components and materials with a negative utilization value - anything that can be re-sold on the market will never find its way back to the producer. Goldsmiths, for example, are dreaming of a legislation that would oblige customers to take their gold jewelry back to the shop - and get rid of it 'free of charge'.

In conclusion: Recycling is a value problem, not a waste problem. A deeper understanding of how to maintain and increase values in loops (assets) will lead to a more sustai-

* Deputy Secretary General, The Geneva Association, Geneva. 
nable economy, through innovative economic strategies that may give a decisive edge in tomorrow's global market. In this case, insurers will miss the chance to create recycling guarantee funds, but find plenty of opportunities to insure innovative technical and commercial strategies within a service economy in loops.

\section{REFERENCES}

Giarinl, O. and STAHEL, W. R. [1989/1993]: "The Limits to Certainty, facing risks in the new Service Economy;" Kluwer Academic Publishers, Dordrecht, Boston, London; ISBN 0-7923-2167-7 (also in French and Italian). 